\title{
(C) OPEN ACCESS \\ Can green space quantity and quality help prevent postpartum weight gain? A longitudinal study
}

\author{
Xiaoqi Feng, ${ }^{1,2,3}$ Thomas Astell-Burt ${ }^{1,2,3,4}$
}

${ }^{1}$ Population Wellbeing and Environment Research Lab (PowerLab), Faculty of Social Sciences, School of Health and Society, University of Wollongong, Wollongong, New South Wales, Australia ${ }^{2}$ Menzies Centre for Health Policy, University of Sydney, Sydney, New South Wales, Australia

${ }^{3}$ Illawarra Health and Medical Research Institute (IHMRI) Illawarra Shoalhaven Local Health District and University of Wollongong, Wollongong, New South Wales, Australia

${ }^{4}$ School of Public Health, Peking Union Medical College, Chinese Academy of Medical Sciences, Beijing, China

\section{Correspondence to} Associate Professor Xiaoqi Feng, Faculty of Social Sciences, School of Health and Society, University of Wollongong, Wollongong, NSW 2522, Australia; xfeng@uow.edu.au

Received 1 June 2018 Revised 23 October 2018 Accepted 22 November 2018 Published Online First 23 January 2019
ABSTRACT

Background Postpartum weight gain is a well-known challenge for many mothers, but associations with green space quantity and quality have not been investigated. Methods This longitudinal study used data on 3843 mothers living in Australia tracked biennially for 15 years post partum from 2004 onwards. Multilevel growth curve models adjusted for confounding were used to examine the patterning of body mass index (BMI) in relation to green space quantity, measured by percentage land use, and green space quality, measured by self-report. Twoway interaction terms were fitted to investigate timecontingent associations between BMI and green space. Results Compared with mothers in areas with $\leq 5 \%$ green space, adjusted BMI coefficients were $-0.43 \mathrm{~kg} / \mathrm{m}^{2}$ (SE 0.37), $-0.69 \mathrm{~kg} / \mathrm{m}^{2}$ (SE 0.32) $-0.86 \mathrm{~kg} /$ $\mathrm{m}^{2}$ (SE 0.33) and $-0.80 \mathrm{~kg} / \mathrm{m}^{2}$ (SE 0.41) among mothers in areas with $6 \%-10 \%, 11 \%-20 \%, 21 \%-40 \%$ and $\geq 41 \%$ green space, respectively. There were no independent associations between BMI and green space quality. Evidence suggested mothers living in areas with $21 \%-40 \%$ green space had the lowest BMI, whether they agreed that local parks were good quality $\left(-0.89 \mathrm{~kg} / \mathrm{m}^{2}(\right.$ SE 0.34$\left.)\right)$ or not $\left(-0.93 \mathrm{~kg} / \mathrm{m}^{2}(\right.$ SE 0.35$\left.)\right)$. Mothers in the greenest areas only had statistically significantly lower BMI if they perceived local parks as high quality $\left(-0.89 \mathrm{~kg} / \mathrm{m}^{2}\right.$ (SE 0.41)). There was limited evidence that these associations varied with respect to the number of years post partum.

Conclusion These findings may suggest that urban greening strategies to achieve a threshold of at least $21 \%$ or more green space in an area may help reduce, but not fully prevent postpartum weight gain. Potential mechanisms warrant investigation.

\section{INTRODUCTION}

There is increasing interest internationally among some public policymakers, health sector decision-makers and scientists of the health benefits of residential green space. ${ }^{1-3}$ This is both in terms of the quantity of green space as well as its quality. Interest is especially strong with regard to prevention of overweight and obesity, which is a major driver of many preventable chronic non-communicable diseases, such as cardiovascular disease and type 2 diabetes. Some work has investigated whether lower body mass index (BMI) is found among people who reside in areas with more green space, ${ }^{4-8}$ with some reporting corroborative evidence. ${ }^{5-7}$ A subset of these studies indicates that the benefits may be stronger for women compared with men (eg, ref 7). Potential mechanisms are likely to include promotion of physical activity and reduction in sedentary behaviour ('instoration'), and components of the 'restoration' and 'mitigation' domain pathways. ${ }^{3}$ For example, some studies report a lower risk of short sleep among people in greener neighbourhoods, ${ }^{9-11}$ which may protect against negative affect, ${ }^{12}$ poor $\operatorname{diet}^{13}$ and weight gain. ${ }^{14}{ }^{15}$ Longitudinal evidence on green space quantity and BMI is, however, limited to a handful of studies (eg, refs 5 8) and none have examined to what extent the quality of green space might matter for preventing weight gain.

The lack of empirical attention to green space quality reflects a general absence of data on a subject that is likely to be contingent on a range of subjectivities and personal experiences that affect what people value. These may, in turn, manifest variation in the potential transactions that occur within green spaces and, henceforth, variation in potential weight gain. For example, women who have recently given birth might have more specific requirements of green spaces that cater to both them and their children, such as good quality amenities, well-maintained footpaths and safe play areas. Although similar qualities might apply across the board, it is plausible that for some population groups such as women in the postpartum period, these qualities may be salient to such a degree that a large quantity of green space nearby judged to be poor quality may have marginal value.

No studies thus far have examined to what extent green space quantity or quality is associated with potential prevention of weight gain among women in the postpartum period. This is surprising, given that weight gain and retention of weight during the postpartum period is recognised as a major health issue. ${ }^{16-18}$ Some recent studies suggest that it is common for gestational weight gain to predict overweight and obesity among women for up to 10-15 years post partum among those who had a 'normal' BMI by WHO standards pre-pregnancy. ${ }^{19-22}$

Accordingly, the aim of this study was to track $\mathrm{BMI}$ in a residentially stable cohort of women from approximately $0-15$ years post partum and to assess associations with measures of green space quantity and quality. There was a specific interest on examining the contingency of any associations between BMI and green space quantity and quality with the number of years post partum, acknowledging that prevention of weight gain would be likely to manifest gradually through time.

\section{METHODS}

A cohort of mothers was extracted from the Longitudinal Study of Australian Children (LSAC), a birth cohort that has tracked approximately 10000 
children and their parents (mostly their mothers) biannually from 2004. ${ }^{23}$ The LSAC was sampled from Medicare, which is the Australian Government's provider of universal healthcare and lists all permanent residents and citizens. Sampling and recruitment involved a two-stage clustered design that was representative of postcodes stratified by state and territory and by capital city statistical division versus rest of the state in 2004, ensuring representation of urban, regional and rural communities. Letters were posted to the households of parents who were randomly selected from the sample postcodes, with $50.4 \%$ recruited, $37.5 \%$ opting out and $15.2 \%$ were uncontactable. Response rates to data collection were $>90 \%$ initially and remained high at $79 \%-80 \%$ by wave 5 , likely due to the use of face-to-face interviews. Data were also collected using mail-out and leave-behind surveys, anthropometric measurements, time-use diaries and interviewer observations. More in-depth information on all aspects of the LSAC is available in the data user guide. ${ }^{24}$

Two cohorts of children and their parents were followed up from 2004 onwards: (1) the 'baby cohort' aged $0-1$ year at baseline; and (2) the 'kindergarten' cohort aged 4-5 years at baseline. The current study focused on the mothers of these children in both cohorts who were the primary survey respondents tracked up to five more waves after baseline in the years 2006 (children aged $2-3$ years and $6-7$ years), 2008 ( $4-5$ years and $8-9$ years), 2010 (6-7 years and $10-11$ years), 2012 (8-9 years and $12-13$ years) and 2014 (10-11 years and 14-15 years). For the purposes of this study, the sample was restricted to 4259 mothers who did not change neighbourhood during this period. This sample was further restricted to 3843 mothers who had complete information on height and weight data for purposes of calculating BMI. Counts of mothers by survey wave were as follows: 2004 $(\mathrm{n}=3317) ; 2006(\mathrm{n}=2832) ; 2008 \quad(\mathrm{n}=3034) ; 2010(\mathrm{n}=3357)$; $2012(\mathrm{n}=3397)$; and $2014(\mathrm{n}=3302)$.

\section{Green space quantity and quality}

The green space quantity variable was based on the percentage of land use within a 'Statistical Area 2' of residence occupied by 'parkland' (excluding agricultural land) according to the Australian Bureau of Statistics (ABS) 2006 meshblock classification. A Statistical Area 2 was designed by the ABS to represent local communities functional areas containing commercial and transport hubs in areas outside of cities, with populations of 10000 on average, ranging from 3000 to $25000 . .^{25}$ Previous research has analysed this green space quantity variable in studies of adolescent mental well-being and general health, BMI, physical activity and asthma, ${ }^{26-32}$ but not in studies of psychological distress, physical activity and BMI among women in the postpartum period. This indicator of green space quantity was categorised into potentially policy-relevant intervals based around a real-world example, used in Perth (Western Australia), in which $10 \%$ of all subdivisible land has been allocated to parks and other open spaces. ${ }^{33}$ These categories were as follows: $<5 \%$; $6 \%-10 \% ; 11 \%-20 \% ; 21 \%-40 \%$; and $\leq 41 \%$.

Green space quality was self-reported on a Likert scale by all mothers in each wave in response to the following statement: 'there are good parks, playgrounds and play spaces in this neighbourhood.' This statement has the advantage of not imposing a priori definitions of what does or does not constitute a quality green space, leaving the judgement on what quality-related factors each parent perceives to be most valuable for them to decide. Likert scale responses were re-expressed as (1) do not agree, (2) agree, or (3) strongly agree.
Some prior research has indicated that green space quality and quantity may be correlated, ${ }^{29} 34$ with larger green spaces being more likely to contain a wider range of amenities and attractions that appeal to a broader cross-section of residents. A third variable was created through cross-classification of the abovementioned measures in an attempt to disentangle potential effects of green space quantity and quality on prevention of weight gain. To avoid problems attributable to small cell sizes, this hybrid variable involved expressions of green space quality as 'do not agree' compared with 'agree or strongly agree' within each stratum of green space quantity.

\section{BMI and adjustment for confounding}

BMI was derived from self-reported height and weight. A range of factors may contribute to the probability that a mother lives in an area with a particular amount of green space and BMI was examined. The most important relate to socioeconomic circumstances and geographic remoteness, which are known to correlate with BMI and may also influence local green space quantity and quality. ${ }^{35-37}$ The Socio-Economic Indexes for Areas relative index of social disadvantage ${ }^{38}$ and the Accessibility/ Remoteness Index of Australia ${ }^{39}$ were used to adjust for arealevel socioeconomic circumstances and geographic remoteness. Person-level socioeconomic circumstances were adjusted using indicators of highest educational qualification, economic status (eg, employed, unemployed) and a binary variable denoting whether a woman had self-identified as Aboriginal or Torres Strait Islander, given the major socioeconomic disadvantages they are known to experience. ${ }^{40}$ Additional adjustment was made for whether or not each mother reported that the study child had a sibling and if there were any new births during the study period, both of which may influence weight gain and neighbourhood selection.

\section{Statistical analysis}

Descriptive tables were used to explore the patterning of BMI and other variables with respect to green space quantity. Missing data on the outcome were omitted. Missing covariate data were modelled using additional categories. BMI was fitted with multilevel linear regression growth curve models in MLwIN V.3.00 $0^{41}$ to account for clustering with three levels: (1) year-specific observations; (2) mother; and (3) area (Statistical Area 2). A 'null' model was initially set up to examine the variance partition coefficient. All confounding variables were then added (model 1 ), with each mother's age and the number of years post partum fitted as mean-centred variables. Square and cubic terms for each of these variables were also included to explore for potential curvilinear associations. This was followed by testing of associations for each of the three green space variables (models 2-4). Contingency in potential associations between BMI and each of the green space variables with respect to the number of years post partum was then investigated using two-way interaction terms. Predicted means from the fully adjusted models were plotted to illustrate these trajectories.

\section{RESULTS}

The mean BMI of the sample was 26.1, which varied by one full BMI point on average between mothers living in the greenest $(25.9 \%)$ and least green $(26.9 \%)$ strata (table 1). This variation is also reflected in the prevalence of overweight and obesity (defined as a BMI>25.0 by the WHO). Perceptions of nearby green space as poor quality appeared to be ' $U$ ' shaped with respect to green space quantity, although strong agreement that 
Table 1 Descriptive statistics

\begin{tabular}{|c|c|c|c|c|c|c|c|c|}
\hline & & Green & Iantity & & & & & \\
\hline & Total & $\leq 5 \%$ & $6 \%-10 \%$ & $11 \%-20 \%$ & $21 \%-41 \%$ & $\geq 41 \%$ & $\mathrm{X}^{2}$ & $P$ value \\
\hline$n$ & 19239 & 3908 & 3121 & 5388 & 4690 & 2132 & & \\
\hline Mean body mass index & 26.1 & 26.9 & 26.2 & 25.8 & 25.8 & 25.9 & & \\
\hline Overweight or obese & (Column percentages) & & & & & & & \\
\hline No & 52.17 & 45.62 & 52.1 & 54.42 & 54.63 & 53.19 & & \\
\hline Yes & 47.83 & 54.38 & 47.9 & 45.58 & 45.37 & 46.81 & 90.246 & $<0.001$ \\
\hline Good parks nearby & (Column percentages) & & & & & & & \\
\hline Disagree & 18.5 & 26.2 & 17.0 & 16.4 & 14.8 & 20.4 & & \\
\hline Agree & 4.7 & 5.1 & 4.2 & 4.6 & 4.6 & 5.0 & & \\
\hline Strongly agree & 76.8 & 68.7 & 78.8 & 79.0 & 80.6 & 74.7 & 231.459 & $<0.001$ \\
\hline Years since childbirth & (Column percentages) & & & & & & & \\
\hline $0-1$ & 8.2 & 8.6 & 8.0 & 8.2 & 8.1 & 8.0 & & \\
\hline $2-3$ & 6.8 & 7.0 & 6.3 & 7.0 & 6.9 & 6.8 & & \\
\hline $4-5$ & 16.5 & 16.5 & 17.0 & 16.6 & 16.1 & 16.2 & & \\
\hline $6-7$ & 16.1 & 15.8 & 16.4 & 16.2 & 16.1 & 16.1 & & \\
\hline $8-9$ & 16.7 & 16.9 & 16.5 & 16.5 & 16.8 & 16.4 & & \\
\hline $10-11$ & 17.4 & 17.5 & 17.3 & 17.4 & 17.4 & 17.4 & & \\
\hline $12-13$ & 9.3 & 9.1 & 9.4 & 9.3 & 9.4 & 9.6 & & \\
\hline $14-15$ & 9.0 & 8.7 & 9.2 & 8.8 & 9.3 & 9.5 & 7.040 & 1.000 \\
\hline Age group (years) & (Column percentages) & & & & & & & \\
\hline $18-34$ & 19.7 & 23.2 & 19.0 & 18.9 & 18.6 & 18.4 & & \\
\hline $35-49$ & 29.3 & 30.2 & 30.1 & 28.8 & 28.7 & 28.8 & & \\
\hline $40-44$ & 30.4 & 29.2 & 31.0 & 30.4 & 31.0 & 30.2 & & \\
\hline$\geq 45$ & 20.7 & 17.5 & 20.0 & 21.9 & 21.6 & 22.6 & 66.294 & $<0.001$ \\
\hline Indigenous status & (Column percentages) & & & & & & & \\
\hline No & 98.7 & 98.5 & 99.2 & 98.7 & 98.5 & 98.3 & & \\
\hline Yes & 1.3 & 1.5 & 0.8 & 1.2 & 1.4 & 1.7 & & \\
\hline Not stated & 0.0 & 0.0 & 0.0 & 0.1 & 0.1 & 0.0 & 17.710 & 0.024 \\
\hline Highest qualification & (Column percentages) & & & & & & & \\
\hline Postgraduate & 16.8 & 12.4 & 20.8 & 18.6 & 17.5 & 13.0 & & \\
\hline Undergraduate & 59.9 & 59.4 & 58.1 & 59.0 & 61.3 & 62.8 & & \\
\hline Year 11-13 & 15.4 & 18.1 & 14.7 & 15.4 & 13.8 & 15.1 & & \\
\hline$\leq$ Year 10 & 7.8 & 10.1 & 6.3 & 6.8 & 7.5 & 9.1 & & \\
\hline Other & 0.1 & 0.0 & 0.0 & 0.2 & 0.0 & 0.1 & 200.649 & $<0.001$ \\
\hline Economic status & (Column percentages) & & & & & & & \\
\hline Employed & 74.1 & 75.0 & 74.5 & 72.6 & 74.1 & 75.8 & & \\
\hline Economically inactive & 23.7 & 22.6 & 23.5 & 25.4 & 23.8 & 21.8 & & \\
\hline Unemployed & 2.1 & 2.3 & 2.0 & 1.9 & 2.1 & 2.3 & & \\
\hline Not stated & 0.1 & 0.1 & 0.0 & 0.1 & 0.0 & 0.1 & 20.036 & 0.066 \\
\hline New birth & (Column percentages) & & & & & & & \\
\hline No & 93.3 & 92.7 & 93.3 & 92.8 & 94.0 & 94.1 & & \\
\hline Yes & 6.7 & 7.3 & 6.7 & 7.2 & 6.0 & 5.9 & 10.527 & 0.032 \\
\hline Sibling(s) present & (Column percentages) & & & & & & & \\
\hline No & 10.1 & 9.6 & 10.8 & 10.4 & 9.4 & 11.0 & & \\
\hline Yes & 89.9 & 90.4 & 89.2 & 89.6 & 90.6 & 89.0 & 7.346 & 0.119 \\
\hline Area disadvantage & (Column percentages) & & & & & & & \\
\hline Affluent & 34.2 & 12.4 & 42.6 & 41.4 & 40.7 & 29.7 & & \\
\hline Average & 33.8 & 33.1 & 32.2 & 31.0 & 39.5 & 32.1 & & \\
\hline Disadvantaged & 32.0 & 54.5 & 25.3 & 27.6 & 19.9 & 38.1 & 1800.000 & $<0.001$ \\
\hline Remoteness & (Column percentages) & & & & & & & \\
\hline Major cities & 65.0 & 37.3 & 78.9 & 71.6 & 74.9 & 56.9 & & \\
\hline Inner regional & 21.0 & 36.7 & 13.2 & 12.7 & 18.9 & 29.2 & & \\
\hline Outer regional or remote & 14.0 & 26.1 & 7.9 & 15.7 & 6.2 & 14.0 & 2200.000 & $<0.001$ \\
\hline
\end{tabular}


Table 2 Multilevel growth curve models of body mass index and associations with the number of years since childbirth, green space quantity and quality, adjusted for confounding

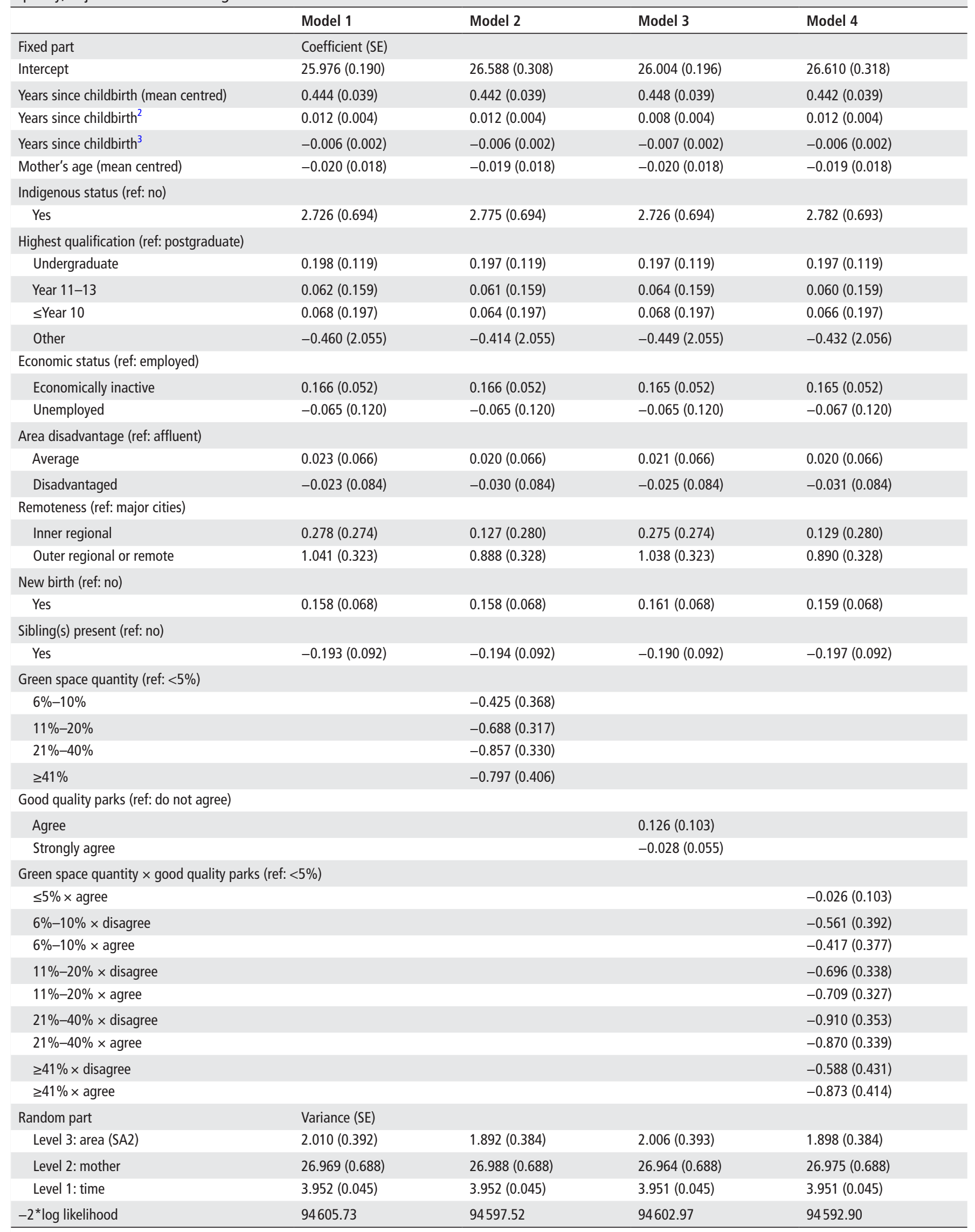

SA2, Statistical Area 2. 
Table 3 Multilevel growth curve models of body mass index and interactions between the number of years since childbirth, green space quantity and quality, adjusted for confounding

\begin{tabular}{|c|c|c|c|}
\hline & Model 5 & Model 6 & Model 7 \\
\hline Fixed part & \multicolumn{3}{|l|}{ Coefficient (SE) } \\
\hline Intercept & $26.594(0.308)$ & $26.011(0.196)$ & $26.619(0.318)$ \\
\hline $\begin{array}{l}\text { Years since childbirth (mean } \\
\text { centred) }\end{array}$ & $0.471(0.043)$ & $0.503(0.044)$ & $0.516(0.053)$ \\
\hline Years since childbirth ${ }^{2}$ & $0.012(0.004)$ & $0.009(0.004)$ & $0.013(0.004)$ \\
\hline Years since childbirth ${ }^{3}$ & $-0.006(0.002)$ & $-0.008(0.002)$ & $-0.006(0.002)$ \\
\hline Mother's age (mean centred) & $-0.019(0.018)$ & $-0.020(0.018)$ & $-0.019(0.018)$ \\
\hline \multicolumn{4}{|l|}{ Indigenous status (ref: no) } \\
\hline Yes & $2.781(0.694)$ & $2.726(0.694)$ & $2.790(0.693)$ \\
\hline \multicolumn{4}{|c|}{ Highest qualification (ref: postgraduate) } \\
\hline Undergraduate & $0.198(0.119)$ & $0.193(0.119)$ & $0.196(0.119)$ \\
\hline Year 11-13 & $0.071(0.159)$ & $0.066(0.159)$ & $0.070(0.159)$ \\
\hline$\leq$ Year 10 & $0.062(0.197)$ & $0.081(0.197)$ & $0.075(0.197)$ \\
\hline Other & $-0.413(2.055)$ & $-0.403(2.055)$ & $-0.439(2.056)$ \\
\hline \multicolumn{4}{|l|}{ Economic status (ref: employed) } \\
\hline Economically inactive & $0.165(0.052)$ & $0.165(0.052)$ & $0.164(0.052)$ \\
\hline Unemployed & $-0.067(0.120)$ & $-0.058(0.120)$ & $-0.064(0.120)$ \\
\hline \multicolumn{4}{|c|}{ Area disadvantage (ref: affluent) } \\
\hline Average & $0.009(0.067)$ & $0.018(0.066)$ & $0.009(0.067)$ \\
\hline Disadvantaged & $-0.031(0.084)$ & $-0.021(0.084)$ & $-0.029(0.084)$ \\
\hline \multicolumn{4}{|l|}{ Remoteness (ref: major cities) } \\
\hline Inner regional & $0.126(0.280)$ & $0.271(0.274)$ & $0.127(0.280)$ \\
\hline Outer regional or remote & $0.887(0.328)$ & $1.032(0.323)$ & $0.884(0.328)$ \\
\hline \multicolumn{4}{|l|}{ New birth (ref: no) } \\
\hline Yes & $0.157(0.068)$ & $0.159(0.068)$ & $0.156(0.068)$ \\
\hline \multicolumn{4}{|l|}{ Sibling(s) present (ref: no) } \\
\hline Yes & $-0.192(0.092)$ & $-0.181(0.092)$ & $-0.188(0.092)$ \\
\hline \multicolumn{4}{|l|}{ Green space quantity (ref: <5\%) } \\
\hline $6 \%-10 \%$ & $-0.427(0.368)$ & & \\
\hline $11 \%-20 \%$ & $-0.694(0.317)$ & & \\
\hline $21 \%-40 \%$ & $-0.862(0.330)$ & & \\
\hline$\geq 41 \%$ & $-0.805(0.406)$ & & \\
\hline \multicolumn{4}{|c|}{ Good quality parks (ref: do not agree) } \\
\hline Agree & & $0.344(0.201)$ & \\
\hline Strongly agree & & $-0.046(0.055)$ & \\
\hline \multicolumn{4}{|c|}{ Green space quantity $\times$ good quality parks (ref: $<5 \%$ ) } \\
\hline$\leq 5 \% \times$ agree & & & $-0.043(0.104)$ \\
\hline $6 \%-10 \% \times$ disagree & & & $-0.569(0.392)$ \\
\hline $6 \%-10 \% \times$ agree & & & $-0.434(0.377)$ \\
\hline $11 \%-20 \% \times$ disagree & & & $-0.691(0.338)$ \\
\hline $11 \%-20 \% \times$ agree & & & $-0.727(0.327)$ \\
\hline $21 \%-40 \% \times$ disagree & & & $-0.930(0.353)$ \\
\hline $21 \%-40 \% \times$ agree & & & $-0.888(0.339)$ \\
\hline$\geq 41 \% \times$ disagree & & & $-0.606(0.431)$ \\
\hline$\geq 41 \% \times$ agree & & & $-0.894(0.414)$ \\
\hline \multicolumn{4}{|c|}{ Years since childbirth $\times$ green space quantity } \\
\hline Years $\times 6 \%-10 \%$ & $-0.010(0.029)$ & & \\
\hline Years $\times 11 \%-20 \%$ & $-0.039(0.025)$ & & \\
\hline Years $\times 21 \%-40 \%$ & $-0.037(0.026)$ & & \\
\hline Years $x \geq 41 \%$ & $-0.070(0.032)$ & & \\
\hline \multicolumn{4}{|c|}{ Years since childbirth $\times$ good quality parks } \\
\hline Years $\times$ agree & & $-0.128(0.063)$ & \\
\hline
\end{tabular}

Table 3 Continued

\begin{tabular}{|c|c|c|c|}
\hline & Model 5 & Model 6 & Model 7 \\
\hline Years $\times$ strongly agree & & $-0.065(0.022)$ & \\
\hline \multicolumn{4}{|c|}{ Years since childbirth $\times$ green space quantity $\times$ good quality parks } \\
\hline Years $\times \leq 5 \% \times$ agree & & & $-0.060(0.042)$ \\
\hline Years $\times 6 \%-10 \% \times$ disagree & & & $-0.039(0.063)$ \\
\hline Years $\times 6 \%-10 \% \times$ agree & & & $-0.059(0.044)$ \\
\hline $\begin{array}{l}\text { Years } \times 11 \%-20 \% \times \\
\text { disagree }\end{array}$ & & & $-0.005(0.054)$ \\
\hline Years $\times 11 \%-20 \% \times$ agree & & & $-0.099(0.041)$ \\
\hline $\begin{array}{l}\text { Years } \times 21 \%-40 \% \times \\
\text { disagree }\end{array}$ & & & $-0.081(0.058)$ \\
\hline Years $\times 21 \%-40 \% \times$ agree & & & $-0.081(0.041)$ \\
\hline Years $\times \geq 41 \% \times$ disagree & & & $-0.035(0.067)$ \\
\hline Years $\times \geq 41 \% \times$ agree & & & $-0.132(0.047)$ \\
\hline Random part & Variance (SE) & & \\
\hline Level 3: area (SA2) & $1.889(0.384)$ & $2.002(0.393)$ & $1.893(0.384)$ \\
\hline Level 2: mother & $26.992(0.688)$ & $26.963(0.688)$ & $26.980(0.688)$ \\
\hline Level 1: time & $3.950(0.045)$ & $3.949(0.045)$ & $3.947(0.045)$ \\
\hline$-2 * \log$ likelihood & 94591.39 & 94592.72 & 94577.62 \\
\hline
\end{tabular}

SA2, Statistical Area 2.

local parks were good quality was lowest among mothers in the areas with the least green space. There did not appear to be any pattern between green space quantity and the number of years since childbirth, economic status or the presence of siblings. Greener areas tended to have a higher percentage of older mothers, mothers with undergraduate degrees, mothers living in urban and/or affluent areas and with a lower prevalence of new births.

Approximately $7.2 \%$ and $79.8 \%$ of the total variance in BMI within the null model was between areas and between mothers, respectively. BMI rose in a curvilinear fashion as the number of years since childbirth increased (table 2, model 1). Mothers who self-identified as indigenous, economically inactive or had more than one child (including a new birth during the time period) had higher BMI on average. Compared with the mothers living in areas with $\leq 5 \%$ green space, those in areas with at least 11\%-20\% green space had lower BMI on average (table 2, model 2). The largest statistically significant effect size for mothers living in areas containing between $21 \%$ and $40 \%$ green space. In contrast, replacing the green space quantity indicator with the measure of quality revealed no statistically significant associations with BMI (table 2, model 3). This non-association between BMI and green space quality was also mostly reflected in the analysis of the cross-classified green space quantity/quality indicator (table 2, model 4), except for mothers living in areas with $\geq 41 \%$ green space, for whom perceptions of quality did make matter for the effect size and statistical significance.

The association between BMI and green space quantity was found to be mostly not contingent on the number of years post partum, except for mothers in the greenest areas for whom the rate of increase in BMI overtime was slightly lower in comparison to their peers in the least green areas (table 3, model 5). There was also some evidence for a time-contingent association between green space quality and BMI, with no statistically significant differences in the early years but with some suggestion of an emerging protective association through time (table 3, model 6). This tendency for a lower rate of increase in BMI over time was also observed for the cross-classified green space quantity/ quality variable (table 3 , model 7). The predicted means from 
A) Green space quantity
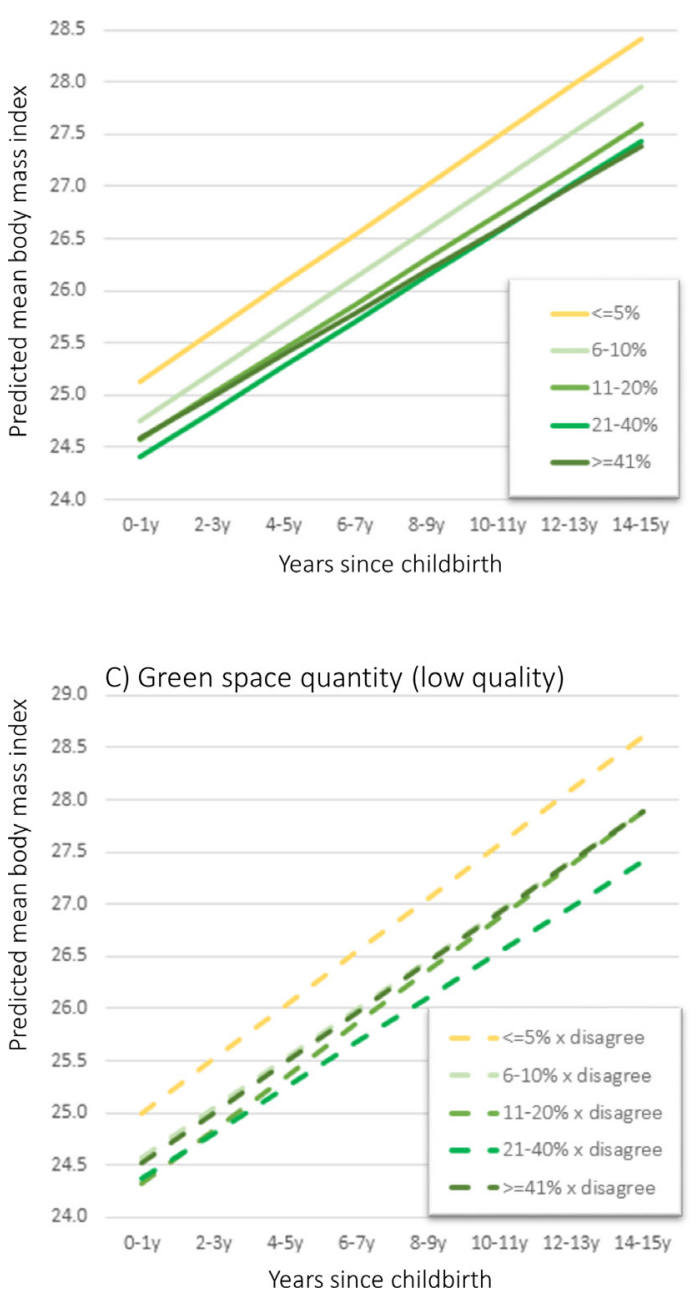

B) Green space quality

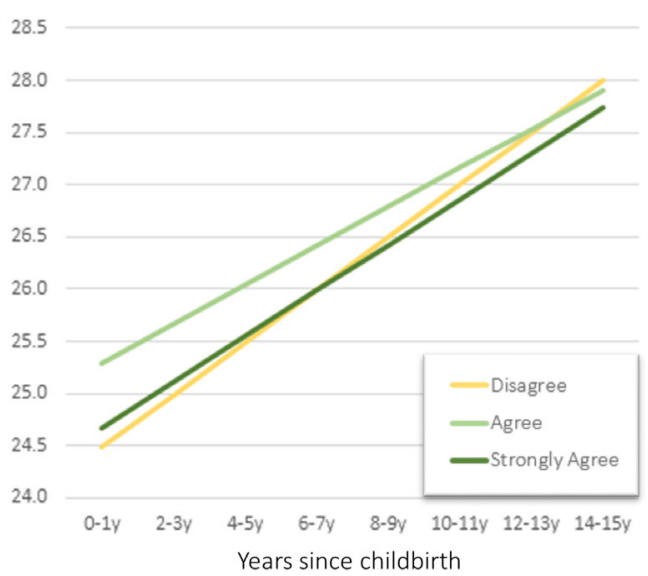

D) Green space quantity (high quality)

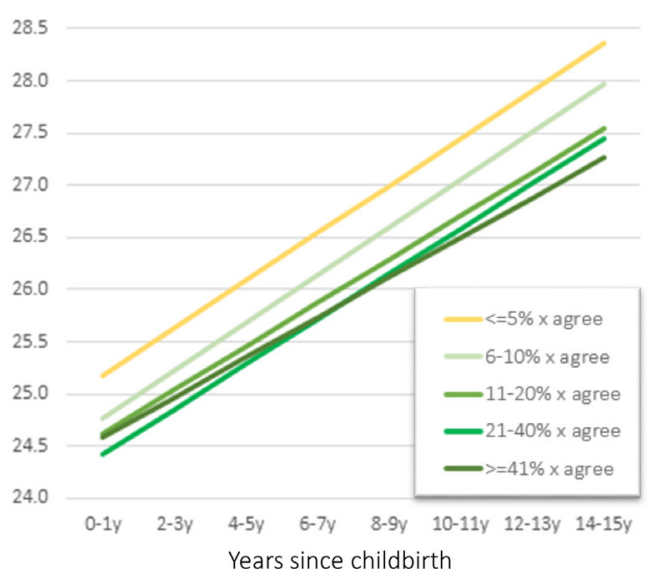

Figure 1 Mean body mass index among women from 1 to 15 years post partum by age, in relation to green space quantity and quality, predicted from adjusted multilevel models.

models 5-7 are shown in figure 1 , in which the time-contingent trajectories in BMI with respect to green space quantity and quality are illustrated.

\section{DISCUSSION}

It was hypothesised that women in the postpartum period with higher quantity and especially those with good quality residential green space would benefit in terms of reduced weight gain. Second, it was anticipated that the benefits of both green space measures would likely take time to manifest. The results provided partial support to hypothesis 1 , with statistically significantly lower BMI observed among mothers living in areas with at least $21 \%-40 \%$ green space, compared with those with $\leq 5 \%$. Surprisingly, no associations were identified between BMI and green space quality, except within the context of areas with $\geq 41 \%$ green space, wherein only those mothers who perceived local parks were good quality had statistically significantly lower BMI. There was little evidence to suggest that these associations varied meaningfully across the study period, suggesting that more green space may promote lower BMI, but may not help to prevent postpartum weight gain.

Strengths and limitations of this study warrant discussion. On limitations, this is an observational study so interpretation of these associations as causal effects must be made with the utmost caution. The green space quantity variable was based on the area of residence, not buffers calculated around the exact location of residence, which may have diluted the effect estimate of green space quantity indicator. However, this limitation would not have affected the non-associations with green space quality, which was self-reported and limited to a single question. It is plausible that were specific questions available regarding more specific qualities of green spaces that mothers may value, such as whether there were good quality amenities, attractive spaces to meet with friends or simply restorative places to relax in, different results may have been found. That said, on strengths, to our knowledge this analysis of a cohort of mothers with respect to green space quantity and quality and potential prevention of postpartum weight gain is the first study of its kind so far. Use of multilevel growth curve models has afforded an explicit insight into potentially time-contingent associations between BMI trajectories and indicators of green space quantity and quality. The study drew on some of the best data available from communities across the whole of Australia.

The findings from this study corroborate with some of those previously reported. A systematic review of evidence published between 2000 and 2010 found 13 studies of green space and BMI, all from the USA, Canada and Europe. ${ }^{4}$ In the studies which examined adults, some observed lower odds of obesity 
among people living in greener areas (eg, ref 42) and these findings have been supported by more recent work, ${ }^{5-7}$ though not all. ${ }^{8}$ Most of the prior work on green space quantity and BMI has been of cross-sectional design and no study has examined women in the postpartum period explicitly, so on these points our study extends the literature significantly. It is also one of the few studies to have been conducted outside Europe and North America on this subject more generally. Another advancement to the literature that has policy relevance is the indication of a potential non-linearity between BMI and green space quantity. Our findings suggest that at least 11\%-20\% green space may be needed to elicit a protective effect of greenery on BMI among women in the postpartum period. The results also indicate that, again for women in the postpartum period, it may be that the strongest benefits and, therefore, the optimal quantity for inclusion in planning guidelines, is for neighbourhoods to contain 21\%-40\% green space (as indicated by the strongest effect size). This policy-relevant observation aligns with work published from the same data set that concluded $21 \%-40 \%$ green space quantity promoted the most favourable levels of mental wellbeing across childhood, ${ }^{29}$ but is less than the amount suggested may be optimal in other studies (eg, for diabetes prevention ${ }^{43}$ ).

The lack of any substantive association between BMI and green space quality, given the results for green space quantity, was quite unexpected. Interactions with green space are argued to be transactional, ${ }^{44}$ in that the frequency and intensity of those interactions are likely to depend on to what extent people regard those green spaces, large and small, as representing and containing the things that enable them to do what they value. On this basis, a measure of green space quality ought to trump quantity when assessed in relation to a health outcome that involves some degree of agency, as is the case with BMI (although the causes of weight status are multifaceted and physical inactivity is but one contributor to the risk of becoming overweight or obese). This view is further supported by some research that found weak correlations when comparing measures of subjective with objective access to green space (eg, ref 45 ). So why was green space quantity important but not quality? We have at least two reflections that may help us to shed some light on these apparently contradictory results.

Our first reflection is that multiple pathways from green space exposures to BMI may be relevant and as a result of becoming better known, will hopefully lead to a deprioritising of the role of agency and a more holistic view on how the health benefits associated with green space can be accrued among policymakers and scientists alike. Perhaps the most intuitive pathway between green space and BMI is physical activity, wherein greener environs are said to exert a gravitational pull for outdoor physical recreation. ${ }^{3}$ Through this lens, green space is viewed as a pleasant setting for the building of capacities, such as via walking and more vigorous exercise. For this pathway, however, and perhaps contrary to popular opinion, the benefits of green space do not have to involve being physically within the green space. It may be that a well-maintained topographically even path running along the perimeter of a park with significant tree canopy or low-lying foliage is equally if not more attractive for walking, jogging and cycling than a less well-maintained, topographically more varied path within the park. Perhaps especially for the sample of mothers with young children in this study who might be pushing prams and walking with their children. This may have a social contagion effect wherein walkable environments and destinations that people have reason to walk to intermesh with green spaces in order to facilitate more liveable communities with stronger perceptions of safety and more opportunities for outdoor recreation and social capital formation. There is evidence that green spaces promote effortless relaxation through visual contact rather than exclusively via emersion within a green setting. But a person does not strictly need to be able to see a green space in order to accrue some benefit, such as restoration from hearing soundscapes associated with biodiversity (eg, birdsong) and the cooling of heat island effects common to cities in warmer regions of the world. In other words, people do not necessarily have to like, nor be able to see green space per se in order to benefit from its presence. These pathways between green space and BMI are likely to interact within positive feedback loops and exert a compound protective effect on BMI and a range of health outcomes in synergy. As such, it seems highly likely that we routinely under-estimate the health benefits of green space.

This argument leads into our second reflection, specifically on the issue of quality. The range of attributes that people value about a green space does not necessarily always have to be good for health. Some aspects of a green space that might be considered markers of good quality for some people might include free Wi-Fi connectivity, barbecue facilities, significant car parking and the availability of cafes and restaurants within green spaces that have ample undercanopy seating. What makes a green space good quality for some people does not necessarily mean that those attributes are good for health. It may also be that the presence of some factors that many people feel is essential for a quality green space actually counts negatively in the perceptions of other people. For example, it would not be surprising to find that green spaces which score highly in terms of the qualities that support participation in sports activities (eg, large open grassy spaces such as a cricket oval, football pitch or outdoor concert venue) also score poorly in terms of the qualities that support restoration (eg, secluded surroundings with lots of trees and gardens). So while the quality measure used in this study has the benefit of permitting each respondent to give an assessment of green space quality according to the factors that matter for them, the inclusion of subsequent questions in the survey on what specific elements of those green spaces are most salient would be a way to enhance future studies.

In conclusion, these reflections are intended to imply that good quality green space does not necessarily always need to equate with good health, perhaps contrary to popular opinion in

\section{What is already known on this subject}

- Postpartum weight gain is a well-known challenge for many women. Some research has indicated that residential green space may contribute to lower body mass index (BMI), but there have been few longitudinal studies on this subject generally and none to have examined the potential benefits of green space quantity and quality for prevention of postpartum weight gain.

What this study adds

- Women in areas with more green space, more so than higher quality green space, tended to have lower BMI, but this did not prevent postpartum weight gain. A threshold of at least $21 \%$ or more green space in an area could be a potential target for promoting healthier weight status. 
the literature. This is evidently an important avenue for further research that aims to advance understandings of what types of green spaces matter for whom and, indeed, how green spaces might be restored and redesigned to optimise population health and well-being.

Acknowledgements This paper uses unit record data from Growing Up in Australia, the Longitudinal Study of Australian Children. The study is conducted in partnership between the Department of Social Services, the Australian Institute of Family Studies and the Australian Bureau of Statistics. We also acknowledge the Australian Bureau of Statistics for use of the 2006 meshblock data.

Contributors XF developed the research question and study design, conducted the statistical analyses and wrote the initial draft of the manuscript. TAB provided critical feedback towards developing the research question and study design, supported the interpretation of the results and had input into manuscript redrafting. Both authors have contributed to, read and approved the final draft.

Funding This project received funding from Hort Innovation with coinvestment from the University of Wollongong (UOW) Faculty of Social Sciences, the UOW Global Challenges initiative and the Australian Government (project number GC15005). XF's contribution to this project was also supported by a National Health and Medical Research Council Career Development Fellowship (No 1148792). XF and TAB are also supported by a National Health and Medical Research Council project grant (No 1101065). TAB is supported by a National Health and Medical Research Council Boosting Dementia Research Leader Fellowship (No 1140317). The study design, analysis, interpretation of data, writing the report and decision to submit the report for publication are of the authors only.

Disclaimer The findings and views reported in this paper are those of the authors and should not be attributed to Department of Social Services, Australian Institute of Family Studies, or the Australian Bureau of Statistics.

Competing interests None declared.

Patient consent for publication Not required.

Ethics approval Department of Social Services.

Provenance and peer review Not commissioned; externally peer reviewed.

Open access This is an open access article distributed in accordance with the Creative Commons Attribution Non Commercial (CC BY-NC 4.0) license, which permits others to distribute, remix, adapt, build upon this work non-commercially, and license their derivative works on different terms, provided the original work is properly cited, appropriate credit is given, any changes made indicated, and the use is non-commercial. See: http://creativecommons.org/licenses/by-nc/4.0/.

\section{REFERENCES}

1 Hartig T, Mitchell R, de Vries S, et al. Nature and health. Annu Rev Public Health 2014;35:207-28.

2 Frumkin H, Bratman GN, Breslow SJ, et al. Nature contact and human health: a research agenda. Environ Health Perspect 2017;125:075001.

3 Markevych I, Schoierer J, Hartig T, et al. Exploring pathways linking greenspace to health: theoretical and methodological guidance. Environ Res 2017;158:301-17.

4 Lachowycz K, Jones AP. Greenspace and obesity: a systematic review of the evidence. Obes Rev 2011:12:e183-9.

5 Halonen JI, Kivimäki M, Pentti J, et al. Green and blue areas as predictors of overweight and obesity in an 8-year follow-up study. Obesity 2014;22:1910-7.

6 Ghimire R, Ferreira S, Green GT, et al. Green Space and Adult Obesity in the United States. Ecol Econ 2017:136:201-12.

7 Astell-Burt T, Feng X, Kolt GS. Greener neighborhoods, slimmer people? Evidence from 246, 920 Australians. Int J Obes 2014:38:156-9.

8 Michael YL, Nagel CL, Gold R, et al. Does change in the neighborhood environment prevent obesity in older women? Soc Sci Med 2014:102:129-37.

9 Astell-Burt T, Feng X, Kolt GS. Does access to neighbourhood green space promote a healthy duration of sleep? Novel findings from a cross-sectional study of 259319 Australians. BMJ Open 2013;3:e003094.

10 Grigsby-Toussaint DS, Turi KN, Krupa M, et al. Sleep insufficiency and the natural environment: Results from the US Behavioral Risk Factor Surveillance System survey. Prev Med 2015;78:78-84.

11 Chum A, O'Campo P, Matheson F. The impact of urban land uses on sleep duration and sleep problems. The Canadian Geographer / Le Géographe canadien 2015:59:404-18.

12 Minkel JD, Banks S, Htaik O, et al. Sleep deprivation and stressors: evidence for elevated negative affect in response to mild stressors when sleep deprived. Emotion 2012;12:1015-20

13 Chaput JP. Sleep patterns, diet quality and energy balance. Physiol Behav 2014;134:86-91.
14 Patel SR, Hu FB, Fb H. Short sleep duration and weight gain: a systematic review. Obesity 2008;16:643-53.

15 Cappuccio FP, Taggart FM, Kandala NB, et al. Meta-analysis of short sleep duration and obesity in children and adults. Sleep 2008:31:619-26.

16 Ohlin A, Rössner S. Maternal body weight development after pregnancy. Int J Obes 1990;14:159-73

17 Gore SA, Brown DM, West DS. The role of postpartum weight retention in obesity among women: a review of the evidence. Ann Behav Med 2003;26:149-59.

18 Gunderson EP, Abrams B. Epidemiology of gestational weight gain and body weight changes after pregnancy. Epidemiol Rev 1999;21:261-75.

19 Endres LK, Straub H, McKinney C, et al. Postpartum weight retention risk factors and relationship to obesity at 1 year. Obstet Gynecol 2015;125:144-52.

20 Mamun AA, Kinarivala M, O'Callaghan MJ, et al. Associations of excess weight gain during pregnancy with long-term maternal overweight and obesity: evidence from 21 y postpartum follow-up. Am J Clin Nutr 2010;91:1336-41.

21 Rooney BL, Schauberger CW. Excess pregnancy weight gain and long-term obesity: one decade later. Obstet Gynecol 2002;100:245-52.

22 Linné Y, Dye L, Barkeling B, et al. Long-term weight development in women: a 15-year follow-up of the effects of pregnancy. Obes Res 2004:12:1166-78.

23 Sanson A, Nicholson J, Ungerer J, et al. Introducing the Longitudinal Study of Australian Children-LSAC Discussion Paper No. 1. 2002

24 Australian Institute of Family Studies. The longitudinal study of australian children: an Australian Government initiative. Canberra: Data User Guide, Australian Government, 2013.

25 Australian Bureau of Statistics. Australian Statistical Geography Standard (ASGS): Volume 1 - Main Structure and Greater Capital City Statistical Areas. Canberra: Australian Bureau of Statistics, 2011.

26 Feng $\mathrm{X}$, Astell-Burt T. The relationship between neighbourhood green space and child mental wellbeing depends upon whom you ask: multilevel evidence from 3083 children aged 12-13 years. Int J Environ Res Public Health 2017;14:235.

27 Feng X, Astell-Burt T. Is neighborhood green space protective against associations between child asthma, neighborhood traffic volume and perceived lack of area safety? Multilevel Analysis of 4447 Australian Children. Int J Environ Res Public Health 2017; 14:543

28 Feng $\mathrm{X}$, Astell-Burt T. Do greener areas promote more equitable child health? Health Place 2017;46:267-73.

29 Feng X, Astell-Burt T. Residential green space quantity and quality and child wellbeing: a longitudinal study. Am J Prev Med 2017;53:616-24.

30 Sanders T, Feng X, Fahey PP, et al. Greener neighbourhoods, slimmer children? Evidence from 4423 participants aged 6 to 13 years in the Longitudinal Study of Australian children. Int J Obes 2015:39:1224-9.

31 Sanders T, Feng X, Fahey PP, et al. Green space and child weight status: does outcome measurement matter? Evidence from an Australian Longitudinal Study. J Obes 2015:2015:1-8.

32 Sanders T, Feng X, Fahey PP, et al. The influence of neighbourhood green space on children's physical activity and screen time: findings from the longitudinal study of Australian children. Int J Behav Nutr Phys Act 2015;12:126.

33 Western Australian Planning Commission. Liveable neighbourhoods: a Western Australian Government Sustainable Cities Initiative. Perth, WA: Western Australian Planning Commission, 2004

34 Giles-Corti B, Broomhall MH, Knuiman M, et al. Increasing walking: how important is distance to, attractiveness, and size of public open space? Am J Prev Med 2005;28:169-76.

35 Mavoa S, Koohsari MJ, Badland HM, et al. Area-level disparities of public open space: a geographic information systems analysis in Metropolitan Melbourne. Urban Policy and Research 2014:1-18.

36 Astell-Burt T, Feng X, Mavoa S, et al. Do low-income neighbourhoods have the least green space? A cross-sectional study of Australia's most populous cities. BMC Public Health 2014:14:292.

37 Crawford D, Timperio A, Giles-Corti B, et al. Do features of public open spaces vary according to neighbourhood socio-economic status? Health Place 2008;14:889-93.

38 Pink B. Socio-Economic Indexes for Areas (SEIFA). Canberra: Australian Bureau of Statistics, 2011

39 Australian Population and Migration Research Centre. ARIA (Accessibility/Remoteness Index of Australia: The University of Adelaide, 2012.

40 Marmot M. Social determinants and the health of Indigenous Australians. Med J Aust 2011;194:512-3.

41 Rasbash J, Browne W, Goldstein H, et al. A user's guide to MLwiN, 2000

42 Ellaway A, Macintyre S, Bonnefoy X. Graffiti, greenery, and obesity in adults: secondary analysis of European cross sectional survey. BMJ 2005:331:611-2.

43 Astell-Burt T, Feng X, Kolt GS. Is neighborhood green space associated with a lower risk of type 2 diabetes? Evidence from 267,072 Australians. Diabetes Care 2014:37:197-201.

44 Hartig T. Nature experience in transactional perspective. Landsc Urban Plan 1993:25(1-2):17-36.

45 Macintyre S, Macdonald L, Ellaway A. Lack of agreement between measured and selfreported distance from public green parks in Glasgow, Scotland. Int I Behav Nutr Phys Act 2008;5:26 